\title{
O Tema Infraestrutura a Partir do Estudo da Realidade
}

\author{
Laís Baldissarelli de Araújo ${ }^{1}$ \\ Cristiane Muenchen ${ }^{2}$
}

\begin{abstract}
Resumo
Neste artigo explora-se como foi realizada a construção curricular de uma escola da rede pública da cidade de Santa Maria/RS a partir dos Três Momentos Pedagógicos (3MP) como estruturantes de currículos. Focaliza-se o primeiro momento pedagógico, denominado Estudo da Realidade, destacando como ocorreu a construção do dossiê para que o tema pudesse ser encontrado. Os instrumentos utilizados para a coleta das informações e construção do dossiê foram: questionários para a comunidade investigada (pais, moradores, posto de saúde, comércio), comunidade escolar (alunos, professores, equipe diretiva, funcionários), conversas informais, análise de documentos da escola, fotografias e entrevistas. Deste processo emergiu o tema Infraestrutura, o qual permeou a construção curricular das disciplinas de Física e Matemática da escola analisada.
\end{abstract}

Palavras-chave: Currículo. Três Momentos Pedagógicos. Estudo da Realidade. Infraestrutura.

THE THEME INFRASTRUCTURE FROM THE STUDY OF REALITY

\begin{abstract}
In this article, we explore how the curriculum construction was carried out in a public school in the city of Santa Maria / RS from the Three Pedagogical Moments (3MP) as structuring of the curriculum. The focus the first pedagogical moment, called Study of Reality, highlighting as was the construction of the dossier so that the subject could be found. The instruments used to collect the information and construction of the dossier were: questionnaires for the investigated community (parents, dwellers, health center, trade), school community (students,
\end{abstract}

1 Mestra em Educação em Ciências, Programa de Pós-Graduação em Educação em Ciências: Química da Vida e Saúde, UFSM, Santa Maria, RS, Brasil. lais_baldissarelli@yahoo.com.br

2 Doutora em Educação Científica e Tecnológica, Departamento de Física, Centro de Ciências Naturais e Exatas, UFSM, Santa Maria, RS Santa Maria, RS, Brasil. crismuenchen@yahoo.com.br 
teachers, management team, employees), informal conversations, school document analysis, photographs and interviews. In this case, the theme that emerged was Infrastructure, which is the theme that permeated the curriculum development of the disciplines of Physics and Mathematics of the analyzed school.

Keywords: Curriculum. Three Pedagogical Moments. Study of Reality. Infrastructure. 
Nos últimos tempos vêm ocorrendo grandes discussões tendo como pauta a necessidade de mudanças no âmbito educacional, pois os resultados apresentados nas escolas são alarmantes, com o índice de evasão, o desinteresse e a repetência dos educandos, bem como a sua desmotivação, que vem aumentando de forma exponencial (MUENCHEN, 2006; MUENCHEN; AULER, 2007; SÃO PAULO, 1990).

Corroborando tais ideias, Pernambuco (1994) destaca que:

A escola pública brasileira tem excluído da plena cidadania, de diferentes formas, parcela significativa de sua clientela. Além de excluir literalmente pela reprovação e pela evasão, prejudica e mesmo exclui de uma atuação qualificada seus contingentes, aprovados ou não, ao não lhes possibilitar acesso real ao conhecimento. Essas três formas de exclusão estão ligadas, não só, mas também, ao papel do conhecimento na prática escolar. A transformação necessária da escola, a nova dinâmica que se impõe, a mudança das práticas escolares, certamente não se restringem às coisas "relativas ao conhecimento" - no entanto, imaginar qualquer transformação que não coloque a questão do conhecimento como pólo central é descaracterizar a função básica da escola (p. 2).

Destas discussões resultam, como possíveis soluções para esses problemas, novas metodologias para o ensino, em que diferentes métodos/ferramentas são apresentados para serem executados nas práticas educativas. Tais soluções, entretanto, somente serão válidas quando os programas escolares, ou seja, os currículos, forem rediscutidos e alterados (AULER, 2007a).

Delizoicov (1982), Delizoicov, Angotti e Pernambuco (2011), Muenchen (2006), Muenchen e Auler (2007), Torres, O’Cadiz e Wong (2002) e Muenchen (2010), são alguns dos autores que destacam a necessidade de mudanças nos programas curriculares das escolas, ressaltando que a construção destes currículos restringe a presença dos educadores e educandos neste processo, possibilitando apenas que suas funções sejam restritas a executores e espectadores dos programas. Para Auler (2007b), nas últimas décadas o currículo tornou-se algo intocável, distante de uma reflexão crítica, quando este é repetido ano após ano, sendo visto como o ideal. 
Como consequência dos currículos "padrões", Freire e Shor (2011) destacam os currículos baseados na transferência de conhecimentos, nos quais a falta de participação dos professores e educandos em sua construção, bem como na organização desses programas, acaba resultando na falta de confiança quanto à criatividade e capacidade dos mesmos, pois, quando os centros de poder estabelecem o que deve ser realizado em classe, sua maneira autoritária impede que o exercício da criatividade entre professores e educandos seja desenvolvido.

Partindo de tais necessidades de mudança, o presente artigo apresenta a utilização - em um processo de reestruturação curricular - da dinâmica dos Três Momentos Pedagógicos (3MP) como estruturantes de currículos, resultante da concepção freiriana para o contexto da educação formal, sendo desenvolvida, inicialmente, por Delizoicov (1982), estando fundamentada pela Abordagem Temática (AT). ${ }^{3}$ A seguir serão apresentados e discutidos os projetos que disseminaram a dinâmica dos 3MP desde seu surgimento até os dias atuais e que corroboraram teoricamente para o presente estudo.

\section{Os Três Momentos Pedagógicos como Estruturantes de Currículos}

A dinâmica dos 3MP origina-se, conforme já destacado, da concepção freiriana para o contexto de educação formal (DELIZOICOV, 1982; MUENCHEN, 2010; MUENCHEN; DELIZOICOV, 2012) e está fundamentada em uma perspectiva denominada por Delizoicov, Angotti e Pernambuco (2011) de AT. Nesta perspectiva, os conteúdos programáticos deixam de ser o fio condutor que define os currículos escolares, que, por sua vez, apresentam características

\footnotetext{
${ }^{3}$ Perspectiva curricular cuja lógica de organização é estruturada com base em temas, com os quais são selecionados os conteúdos de ensino das disciplinas. Nesta abordagem, a conceituação científica da programação é subordinada ao tema (DELIZOICOV; ANGOTTI; PERNAMBUCO 2011, p. 189).
} 
de currículos tradicionais que se encontram distantes e descontextualizados da realidade dos educandos e passam a ser construídos a partir de temas ${ }^{4}$ que surgem da realidade dos estudantes.

Esses momentos, por incorporarem a concepção dialógica e problematizadora de Paulo Freire (2011), se desenvolvidos de forma dialógica e a partir da realidade do educando, podem fortalecer o processo de ensino/aprendizagem, contribuindo para o desenvolvimento do senso crítico e para a superação dos níveis de consciência pelo educando (GIACOMINI, 2014). Freire (2011) enfatiza que, no nível de "consciência real efetiva", os sujeitos limitam-se a perceber além das "situações-limites", sendo caracterizado este momento como "inédito viável" e, para a busca de uma transformação e formação crítica, torna-se necessário que a construção do conhecimento possibilite que os sujeitos atinjam a "consciência máxima possível”.

\section{A origem dos Três Momentos Pedagógicos}

De acordo com Delizoicov (1982), o projeto "Formação de Professores de Ciências Naturais", desenvolvido na Guiné-Bissau junto ao Centro de Educação Popular Integrada (Cepi), ${ }^{5}$ destinava-se à formação de professores e à produção de material didático e tinha como tentativa pôr em prática uma proposta pedagógica de acordo com a concepção problematizadora de Paulo Freire em um contexto de educação formal ao nível de $5^{\mathrm{a}}$ e $6^{\mathrm{a}}$ séries de $1^{\mathrm{o}}$ grau em Ciências Naturais.

${ }^{4}$ Destaca-se que os temas emergentes da realidade dos educandos são caracterizados também como conteúdos a serem trabalhados, nos quais os conceitos científicos encontram-se como meios para que seja possível a compreensão do tema emergente da realidade investigada.

5 No ano de 1978, como estagiários do Instituto de Recherche, Formation, Education et Developpement (Irfed), Demétrio Delizoicov e José André Angotti vivenciaram uma experiência educacional na Guiné-Bissau, no Centro de Educação Popular Integrada (Cepi). Após esta experiência, retornaram, em maio de 1979, à Guiné-Bissau, Demétrio Delizoicov e Nadir Castilho, seguidos por José André Angotti e Isaura Simões, para coordenarem o projeto "Formação de Professores de Ciências Naturais", sendo este projeto posteriormente relatado e analisado por Delizoicov (1980, 1982) e Angotti (1982) em suas dissertações de Mestrado (MUENCHEN, 2010; MUENCHEN; DELIZOICOV, 2012). 
O Cepi apresentava um modelo de escola de $5^{\mathrm{a}}$ e $6^{\mathrm{a}}$ séries do $1^{\mathrm{o}}$ grau que atendia às necessidades do meio rural, sendo ainda um centro de formação de professores, os quais eram formados na prática. Não ocorria a clássica divisão de disciplinas, com sua estrutura sendo apresentada em quatro grandes áreas ligadas ao meio rural, quando o currículo era estruturado desde as vivências da população e as disciplinas eram trabalhadas a partir dos temas, não estando compartimentadas em departamentos estanques (DELIZOICOV, 1982, 1991).

Neste centro era utilizado o "roteiro pedagógico" para a realização das atividades escolares, o qual consistia em três momentos: "Estudo da Realidade" (ER), “Estudo Científico" (EC) e "Trabalho Prático” (TP).

Após a realização de testes quanto à viabilidade da utilização deste roteiro, ele foi adotado para a construção das atividades desenvolvidas no projeto, o qual tinha como objetivos promover o ensino de Ciências baseado na realidade dos alunos e professores, identificar e compreender, no coletivo com os educadores, aspectos relevantes da comunidade guineense, produzir material experimental ligado ao ensino de Ciências e desenvolver alguns aspectos de uma metodologia para o ensino de Ciências, em que o diálogo problematizador estivesse presente (DELIZOICOV, 1982).

Após algumas incorporações e mudanças no roteiro, teve origem o que, hoje, denominamos de Três Momentos Pedagógicos (3MP):

Com a interpretação que fazíamos (em 1975) do processo de codificação-problematização-descodificação, isto é, que deveria estruturar o diálogo em torno do fenômeno e/ou situação, procurávamos alternativas para a sua aplicação em sala de aula. Com o desenvolvimento do projeto "ensino de ciências naturais na Guiné Bissau" (Delizoicov, 1982) foi possível conceber o que temos denominado de momentos pedagógicos (DELIZOICOV, 1991, p. 182-183). 
Das mudanças e apropriações ocorridas pelos 3MP, a partir do roteiro pedagógico utilizado pelo Cepi, destacam-se, segundo Delizoicov (1982), a incorporação da dialogicidade em cada um dos momentos e a mudança de nomenclatura do terceiro momento denominado Trabalho Prático para Aplicação do Conhecimento.

Com as primeiras mudanças realizadas no "roteiro pedagógico" que possibilitaram o surgimento dos 3MP, posteriormente esta dinâmica foi empregada em outros projetos, os quais extrapolaram a sua utilização inicial, ampliando seu uso no processo dinâmico como um todo.

\section{Os Três Momentos Pedagógicos e o Projeto "Ensino de Ciências a Partir de Problemas da Comunidade": Avanços Alcançados}

No período compreendido entre 1984 e 1989 foi introduzido o projeto denominado "Ensino de Ciências a Partir de Problemas da Comunidade" (ECPC), coordenado, inicialmente, por Cristina Dal Pian e, posteriormente, por Marta Pernambuco nos municípios de São Paulo de Potengi e Natal, no Estado do Rio Grande do Norte. Este projeto tinha como objetivo a construção coletiva, com os professores das quatro primeiras séries do Primeiro Grau, para adaptar os conteúdos de Ciências Naturais à realidade da comunidade (MUENCHEN, 2010; PERNAMBUCO, 1994). O roteiro utilizado inicialmente na Guiné-Bissau, denominado Três Momentos Pedagógicos (3MP), neste projeto, foi empregado além das proposições iniciais, resultado das reflexões realizadas que permitiram um aprofundamento de seu significado (DELIZOICOV, 1991; PERNAMBUCO, 1994).

Entre as modificações ocorridas houve a alteração da nomenclatura do segundo momento denominado "Estudo Científico" para "Organização do Conhecimento", pois se percebeu que este momento não era mais científico do que os outros, principalmente tratando-se da "Aplicação do Conhecimento" 
(DELIZOICOV, 1991). Nesse sentido, Delizoicov acentua que não ocorreu uma simples mudança de denominação, pois isso "permitiu um salto qualitativo na nossa própria percepção do trabalho até então realizado" (1991, p. 185).

Das mudanças ocorridas durante o Projeto no Rio Grande do Norte, constata-se um avanço em relação ao emprego dos 3MP quanto a sua utilização inicial, a qual tinha como função estruturar as atividades que eram desenvolvidas em sala de aula. Pernambuco (1994) salienta que o uso dos 3MP não se restringe às atividades de sala de aula ou à organização de programas escolares. Estes podem ser empregados também para organizar reuniões, desencadear um processo na escola ou planejar o trabalho das equipes.

Muenchen (2010) destaca também que

[...] a partir do trabalho conjunto entre o grupo de investigadores no Ensino de Ciências e os professores participantes dos projetos, ficou claro que cada um dos momentos: estudo da realidade, organização do conhecimento e aplicação do conhecimento, aplicado para uma situação ampla, como o programa de uma série, contém dentro de si novamente os outros três (p. 117).

Com isso, a dinâmica dos 3MP neste projeto apresentou um papel importante em todas as etapas da construção e desenvolvimento das práticas educativas que eram elaboradas, ou seja, os momentos estavam incorporados na programação da série, bem como nas atividades desenvolvidas em sala de aula. Pernambuco (1994) apresenta um exemplo do que é destacado por Muenchen:

[...] a organização do conhecimento da $5^{\mathrm{a}}$ série vai se subdividir novamente em três momentos, agora para pensar como explorar os conteúdos específicos gerados no estudo da realidade anterior e assim sucessivamente, cada aula, cada atividade é organizada, repetindo a sequiência fala do aluno, fala do professor, reconstrução conjunta (2010, p. 136).

Durante o desenvolvimento do projeto "Ensino de Ciências a Partir de Problemas da Comunidade", constata-se grandes avanços da dinâmica quanto a sua utilização e disseminação. 
Muenchen e Delizoicov (2012) destacam que, no decorrer do projeto "Formação de professores de Ciências Naturais", ocorreu a "incorporação" dos 3MP ao processo de Investigação Temática (IT) (FREIRE, 2011). Como os momentos pedagógicos encontram-se inseridos numa concepção transformadora da educação, torna-se imperativo o aprofundamento da sua relação com a construção do currículo escolar. A seguir será explorado o Projeto de Reorientação Curricular realizado na cidade de São Paulo, no período compreendido entre 1989 e 1992, no qual os 3MP estavam presentes em todas as etapas da construção curricular das escolas envolvidas no projeto.

\section{O Movimento de Reorientação Curricular a partir dos Três Momentos Pedagógicos: da estruturação dos currículos escolares à dinâmica de sala de aula}

O Movimento de Reorientação Curricular (MRC), conhecido como Projeto "Interdisciplinaridade via Tema Gerador" ou Projeto Inter, teve início em 1989 e perdurou até 1992 no munícipio de São Paulo/SP, quando o educador Paulo Freire foi secretário da Educação da capital paulista. A gestão em que Freire era secretário tinha como princípios norteadores a participação democrática e a construção coletiva, além de que um de seus objetivos políticos era a democratização das escolas, o que implicava um processo de reformulação curricular que exigia a participação de toda a comunidade escolar, para que isso se tornasse um projeto educativo consistente (TORRES; O'CADIZ; WONG, 2002; ARAÚJO; MUENCHEN, 2013).

O MRC tinha como modelo de trabalho a reforma curricular das escolas baseada num currículo interdisciplinar construído a partir do que Freire (2011) define como tema gerador. Essa construção apresentava como base o trabalho coletivo, o diálogo, a problematização e a participação de todos os envolvidos, e ainda estimulava os docentes a perceberem a importância de se realizar reflexões sobre suas práticas pedagógicas (TORRES; O'CADIZ; WONG, 2002). 
Neste projeto, os 3MP estavam presentes em todas as etapas do desenvolvimento, ou seja, eram utilizados como estruturantes dos currículos para a definição dos temas a serem trabalhados nas escolas e como dinâmica para a elaboração dos planejamentos das áreas, das disciplinas e no desenvolvimento das atividades em sala de aula, conforme é apontado por Muenchen:

[...] os 3MP estavam implícitos em todos os aspectos pedagógicos do Projeto Inter, ou seja, não apenas revelavam a forma como os professores formados conduziam seus esforços na construção curricular como também constituíam a estrutura que guiava o processo como um todo. Logo, pode-se afirmar que os três momentos orientavam tanto o desenvolvimento curricular geral como o trabalho específico de sala de aula (2010, p. 120).

Torres, O'Cadiz e Wong destacam o emprego dos Momentos Pedagógicos durante o desenvolvimento curricular, bem como das atividades de sala de aula do Projeto Inter:

[...] estes momentos marcavam os passos dados na implementação de um projeto de currículo interdisciplinar, tanto em sentido lato, de desenvolvimento curricular geral, como no contexto específico da atividade da sala de aula (2002, p. 140).

Como estruturantes de currículos, os momentos pedagógicos são conhecidos como: Estudo da Realidade (ER), Organização do Conhecimento (OC) e Aplicação do Conhecimento (AC).

Estudo da Realidade (ER): Este primeiro Momento Pedagógico do desenvolvimento curricular é destinado a obter informações sobre a comunidade na qual está inserida a escola. Esta investigação ocorre a partir de um dossiê que contém entrevistas, questionários, conversas informais, análises de documentos, visitas a igrejas, centros comunitários, IBGE. Além disso, são investigados os interesses, objetivos, expectativas da comunidade escolar. Num segundo momento os docentes, no coletivo, codificam as situações significativas obtidas do dossiê e, como resultado, chega-se ao tema gerador em torno do qual será construído o currículo da escola (MUENCHEN, 2010; MUENCHEN; DELIZOICOV, 2012; ARAÚJO; MUENCHEN, 2013). 
Organização do Conhecimento $(O C)$ : Na Organização do Conhecimento são utilizados os dados que emergiram do ER para que o coletivo de professores possa definir quais serão as questões geradoras e os conteúdos específicos que deverão ser trabalhados para a compreensão do tema gerador. Este momento destina-se aos planejamentos por áreas (MUENCHEN, 2010; MUENCHEN; DELIZOICOV, 2012; ARAÚJO; MUENCHEN, 2013).

Este momento tem como finalidade a inter-relação entre os temas e as situações vivenciadas pela comunidade com os conteúdos a serem trabalhados, buscando, com isso, a compreensão da realidade.

Muenchen (2010) destaca ainda a importância desta segunda etapa do desenvolvimento curricular:

Ao sintetizar esta etapa, pode-se afirmar que o estudo problematizado dos dados levantados sobre a comunidade apresenta situações significativas, que precisam ser organizadas e analisadas, situando-as no contexto da realidade, assim como ao nível macro social ou global. É esse trabalho que entusiasma um diálogo interdisciplinar, ou seja, o tema desafia as disciplinas a selecionar e integrar conhecimentos, permitindo assim uma leitura crítica da realidade (p. 127).

Assim, as informações coletadas da comunidade no ER são abordadas pelas disciplinas, possibilitando que o tema emergido destas informações seja compreendido, potencializando ao educando uma compreensão crítica não só da realidade que o cerca, mas também de um cenário que engloba situações macrossociais.

Aplicação do Conhecimento (AC): a última etapa do desenvolvimento curricular é destinada à execução das atividades em sala de aula e à avaliação do programa, avaliação caracterizada também pela "planificação de actividades que demonstrem as construções de conhecimento" (TORRES; O'CADIZ; WONG, 2002, p. 148). 
Muenchen (2010) ressalta que existe uma relação dinâmica entre a organização curricular e a prática de sala de aula tratando-se dos momentos pedagógicos. Os 3MP, além de guiarem a estruturação curricular, também são utilizados pelos educadores na instituição de um currículo interdisciplinar, como uma ferramenta metodológica para a sala de aula.

Com o desenvolvimento do Projeto Inter foi possível constatar que não somente os planejamentos das aulas podem estar estruturados a partir dos 3MP, mas também o currículo escolar, possibilitando que este seja construído de forma interdisciplinar e dialógica a partir de problemas que estão em contato com os educandos. Com isso, ao explorar a realidade concreta dos alunos, tornando-a objeto de estudo, possibilita-se que seja aguçada a sua curiosidade epistemológica (FREIRE, 1992), dimensão central no ato de aprender, fortalecendo o processo de ensino/aprendizagem e estimulando a cultura de participação.

\section{Metodologia}

Este artigo originou-se de uma pesquisa mais ampla, em âmbito de Mestrado (ARAÚJO, 2015), que desenvolveu um processo formativo ${ }^{6}$ com docentes de Física e Matemática de uma escola da rede pública da cidade de Santa Maria/ RS utilizando os 3MP na organização curricular e também como ferramenta didático-pedagógica para a sala de aula. $\mathrm{O}$ foco do artigo concentra-se em explanar como foi realizado o primeiro Momento Pedagógico na estruturação curricular, denominado Estudo da Realidade (ER), destacando como o tema Infraestrutura emergiu deste processo.

A pesquisa fundamenta-se, segundo Gil (2002), numa abordagem de cunho qualitativo e exploratória. Para a coleta dos dados que compôs o dossiê do ER foram utilizados questionários (Anexo 1) para a comunidade investiga-

${ }^{6}$ Desenvolvido no departamento de Física da Universidade Federal de Santa Maria, com projeto registrado no Gabinete de Projetos do Centro de Ciências Naturais e Exatas sob o nº 035206. 
da (pais, moradores, posto de saúde, comércio), comunidade escolar (alunos, professores, equipe diretiva, funcionários), conversas informais, análise de documentos da escola, fotografias e entrevistas.

Buscou-se, com o desenvolvimento desta pesquisa, possibilitar que os educadores de uma escola pública da rede estadual da periferia da zona sul de Santa Maria/RS percebessem que o seu papel docente não se limitava apenas à sala de aula. Seu papel concentrou-se em ser sujeito ativo no processo de construção curricular da escola com base na dinâmica dos 3MP, permitindo aos educandos um ensino pautado pelo diálogo e problematização.

Para que esse processo fosse desenvolvido foi realizado um curso de formação de 40 horas com o objetivo de construir o currículo da escola investigada de forma coletiva e interdisciplinar a partir dos 3MP. O convite para participação no curso estendeu-se a todas as áreas de ensino e para os turnos da manhã e da tarde, visto que a atividade visava ao trabalho coletivo e interdisciplinar, porém participaram do curso apenas 3 (três) docentes: ${ }^{7} 2$ (duas) professoras da disciplina de Física e 1 (uma) professora da disciplina de Matemática.

Pelo motivo da escola proporcionar uma organização curricular que apresenta aspectos que estão em sintonia com alguns dos objetivos da dinâmica dos 3MP, tais como o trabalho coletivo e interdisciplinar, a estrutura do local possibilitou que o projeto fosse desenvolvido de forma mais aceitável e compreensível comparado às escolas que apresentam um perfil tradicional e propedêutico de ensino. Constata-se em um trecho do Projeto Pedagógico da escola a aproximação com os objetivos dos 3MP:

Dá-se prioridade para um trabalho interdisciplinar, isto é, o trabalho realizado em sala de aula será desenvolvido de forma globalizada agrupando-se disciplinas afins que compõem cada área. Cada disciplina terá seu professor específico que trabalharão em conjunto em sala de aula.

\footnotetext{
7 Ressalta-se que este número não foi maior em virtude, de os docentes apresentarem uma carga
} horária de trabalho máxima, dificultando, com isso, a participação nos encontros do curso. 
Cada área terá dois blocos/semanal em cada série. Portanto, a carga horária é distribuída igualmente em todas as áreas de estudo (RIO GRANDE DO SUL, 2011, p. 11).

A seguir são apresentados os resultados do processo de "mergulho" na realidade investigada, utilizando a dinâmica dos 3MP como estruturantes de currículos. Com base no tema emergido da comunidade analisada buscou-se discutir com os educandos os problemas que a comunidade enfrentava e, a partir das discussões e das atividades realizadas, possibilitar que estes sujeitos tornem-se cidadãos capazes de intervir e modificar a sociedade em que se encontram inseridos.

\section{O Estudo da Realidade e o surgimento do tema gerador}

Com o objetivo de estruturar o currículo da escola com base nos 3MP, o ER foi desenvolvido de forma coletiva e interdisciplinar pelos educadores (de Física e Matemática) envolvidos no processo formativo.

O ER teve início com a elaboração dos questionários (Anexo 1) para a comunidade local e a comunidade escolar na qual o projeto estava sendo posto em prática. Após alguns encontros teóricos de discussões sobre como construir um currículo com base nos $3 \mathrm{MP}$ e de algumas leituras que sustentaram a proposta, foi dado início a este processo. Foi destinado um encontro de 4 horas para que fosse elaborado o material para coleta dos dados (Anexo 1). Primeiramente, antes da organização dos questionários que fariam parte do dossiê, ocorreu uma discussão com o grupo de docentes, quando foram abordados aspectos sociais, econômicos, culturais e políticos que estavam presentes naquela comunidade, possibilitando, com isso, um mergulho mais aprofundado em relação à realidade investigada.

É importante ressaltar que as três docentes participantes do projeto trabalhavam na escola havia um determinado tempo e conheciam, de forma sucinta, o bairro em que a escola estava inserida, bem como os alunos que frequentavam a escola. Mesmo, porém, estas docentes apresentando um conhecimento prévio 
sobre a realidade dos educandos, Araújo (2015) destaca a necessidade apontada por elas, de um contato mais próximo com a realidade dos estudantes. Isso foi constatado nas entrevistas realizadas com as docentes:

Eu acho que embora eu não me achasse tão longe deles, eu acho que essa maior aproximação foi que me levou a discutir situações da vida deles, que se eu não tivesse ido à comunidade eu não saberia né, como essa fragilidade social que eles têm. E aí, eu acho que forço uma aproximação maior, e essa aproximação maior tornou eles mais receptivos [...] (PROF. 1).

Após discussão decidiu-se que as entrevistas seriam destinadas à comunidade local de onde os educandos emergiam (comerciantes, pais dos educandos, moradores do bairro), ao posto de saúde da comunidade e à comunidade escolar. Posteriormente à etapa de elaboração dos questionários, as docentes e a pesquisadora, juntamente com alguns alunos, aplicaram o questionário com a comunidade local. Este processo perdurou por quatro dias. Durante esta etapa ocorreram conversas informais com os moradores, comerciantes, pais de alunos sobre os problemas enfrentados por eles na comunidade, bem como quais poderiam ser as propostas de soluções para tais problemas. Nesse momento ocorreu o reconhecimento mais aprofundado da comunidade pelas docentes. A seguir são apresentadas algumas falas que apontam para as situações descritas anteriormente:

A sanga que passa aqui atrás tinha que ser diferente, a prefeitura teria que colocar tubos, pois o esgoto desce tudo aqui a céu aberto e isso tem um cheiro muito ruim. Além disso, os ônibus também não estão muito bons, os ônibus entram aqui de hora em hora e estão sempre superlotados, eles teriam que colocar mais horários de ônibus (MORADOR 3).

É preciso ter mais segurança, sabe, a droga rola solta e o policiamento quase não aparece. A segurança aqui está complicada [...] Acho que poderiam arrumar as ruas também, porque quando chove alaga tudo aqui na frente do bar (COMERCIANTE). 
Ainda, durante esta etapa, foram fotografados alguns lugares da comunidade que apresentavam problemas estruturais e que haviam sido bastante mencionados pelos moradores como sendo aspectos que deveriam ser resolvidos. Este momento possibilitou que as docentes envolvidas no processo se tornassem investigadoras da realidade de seus educandos, possibilitando com isso a construção de um diálogo problematizador sobre as dificuldades enfrentadas no bairro.

Após finalizar o mergulho na comunidade, arquivar os registros dos problemas apresentados no bairro, deu-se início à coleta dos dados da escola. Para isso realizaram-se entrevistas com a equipe diretiva, professores, funcionários e estudantes. Esta etapa durou dois dias. As entrevistas com os estudantes foram realizadas com todos os alunos do Ensino Médio da escola, possibilitando, com isso, maior aprofundamento dos dados.

Juntamente com entrevistas realizadas na escola, fez-se uma análise dos documentos da instituição, nos quais foram observados seus objetivos, o perfil apresentado pelos educandos, bem como a história da escola. A seguir são apresentados trechos das entrevistas, que apontaram os problemas vivenciados na comunidade escolar:

Em dias de chuva temos um grande número de alunos que não vêm para a escola porque eles sofrem com os alagamentos e não conseguem sair de suas casas. Acredito, que dentre os problemas que enfrentamos, esse seja um dos que mais atrapalham (PROF. 4).

Existe um grande número de alunas grávidas, acredito que seja um problema que nos afeta também (PROF. 2).

Poderia ter mais segurança aqui na frente da escola, na faixa, sabe. Ter um guarda na entrada e saída da aula (EQUIPE DIRETIVA).

Ao término das entrevistas, das conversas informais, da análise de fotografias e de documentos - materiais que faziam parte do dossiê -, foi dado início à segunda etapa que compõe o ER. Com os dados coletados iniciou-se a categorização das informações recolhidas pelo dossiê. Esta etapa ocorreu em um encontro de 4 horas, no qual foram analisados todos os materiais coletados. 
Torna-se importante ressaltar que este processo consistiu em aproximar as semelhanças obtidas, verificar quais eram os problemas que haviam sido mencionados de forma significativa, analisar as fotos coletadas e os documentos examinados.

De todo este processo de categorização de dados, ou seja, de reunir todo o material para verificar quais eram, de fato, as situações significativas para aquela comunidade, emergiram diversos problemas, entre os quais drogas, segurança, transporte, saúde, rede de esgoto, lixo. Verifica-se nos trechos a seguir falas da comunidade local e da comunidade escolar sobre os problemas enfrentados:

É isso aí que vocês estão vendo, a gente paga os impostos tudo certinho e o que a gente tem em troca? Esse esgoto que corre nas valetas a céu aberto transmitindo doenças. No verão, vocês não imaginam o cheiro que isso causa (COMERCIANTE).

Para conseguir consultar no postinho, a gente precisa estar de madrugada lá para conseguir uma ficha. $\mathrm{E}$, às vezes, o posto abre e a fila tá tão grande que não conseguimos consulta, pois tem um número máximo de fichas (MORADOR 1).

Nós temos um problema muito sério com os alagamentos aqui na frente da escola, pois quando chove a rua aqui fica toda alagada e fica difícil chegar até a escola (EQUIPE DIRETIVA).

A rua lá na frente da minha casa quando chove vira um rio, ninguém consegue sair de casa. Sem contar os buracos que têm na rua (ALUNO 1).

O maior problema pra mim é o esgoto do Arroio Cadena que passa atrás da minha casa, o cheiro é muito ruim. E também o que precisa ser mudado é o transporte, porque as passagens estão muito caras e os ônibus estão horríveis (ALUNO 2).

O transporte está bem complicado, os ônibus estão superlotados, os horários para chegar até a escola são bem limitados e a passagem está com um preço bem alto. Sem contar que os ônibus estão em péssimas condições de uso (PROF. 1).

$\mathrm{Na}$ época de eleição os candidatos vivem aqui fazendo promessa. Na última eleição o prefeito que se elegeu prometeu que faria calçamento aqui na frente. Dá uma olhada na estrada, toda cheia de buracos e nada do calçamento, depois que passam as eleições a gente aqui do bairro é esquecido (MORADOR 2). 
Quando chove demais o ônibus não consegue me pegar para vir para a aula, porque eu moro para fora e as estradas são horríveis, daí quando tem muita chuva o ônibus não chega porque atola (ALUNO 3).

Após a análise das situações significativas, o tema que o grupo verificou ser um problema imerso na localidade, a partir da inter-relação dos dados coletados nas situações que representassem o cotidiano da comunidade investigada, da consideração da frequência com que os dados apareceram e a consideração da não frequência quanto ao indicador de contradições (SÃO PAULO, 1990; TORRES; O’CADIZ; WONG, 2002; MUNCHEN, 2010), foi Infraestrutura.

Infraestrutura caracteriza-se por um grande tema que abarca subtemas em seu interior, conforme se constata no esquema a seguir:

Figura 1 - Esquema que sintetiza o tema Infraestrutura e os subtemas incorporados a este

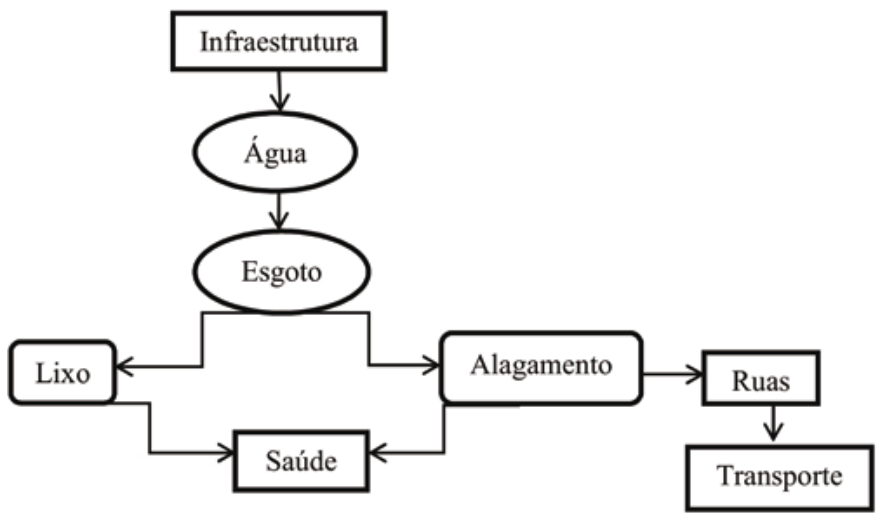

Fonte: ARAÚJO, 2015, p. 71.

Almejou-se com o desenvolvimento do tema Infraestrutura discutir com os educandos os problemas que a comunidade enfrentava e, a partir das discussões e das atividades realizadas, possibilitar que estes sujeitos tornem-se cidadãos capazes de intervir e modificar a sociedade em que se encontram inseridos. Com isso, verificou-se que o tema Infraestrutura caracteriza-se como de natureza social e político, pois, de acordo com Halmenschlager, os temas desta natureza: 
Diferentemente dos temas de natureza conceitual e contextual, a dimensão social tem como pretensão, em geral, a conscientização acerca das decorrências sociais submergidas no tema. A dimensão política é contemplada quando a temática, para além de trazer ao estudo os aspectos sociais, assume o compromisso com a transformação, mediante várias formas de pretensão. Em outras palavras, as questões e os aspectos desenvolvidos a partir do tema têm por finalidade maior a tomada de consciência acerca do problema, incluindo a discussão de perspectivas para uma intervenção na realidade concreta (2014, p. 137).

Nesse mesmo sentido, segundo Araújo e Muenchen (2014), o tema Infraestrutura por emergir da Investigação da Realidade, a qual abarca os problemas da comunidade dos educandos, é entendido como sendo um tema gerador. $\mathrm{O}$ tema é de fato caracterizado como gerador por apresentar manifestações locais da realidade concreta dos educandos, propiciando, com isso, um estímulo ao que Freire (1992) denomina de curiosidade epistemológica.

O tema apresenta ainda características que se aproximam daquilo que o Pensamento Latino-Americano em Ciência, Tecnologia e Sociedade (Placts) ${ }^{8}$ busca: a problematização de aspectos relacionados às necessidades da população para a construção de uma agenda de pesquisa local e a participação dos sujeitos nas tomadas de decisão sobre uma Política Científico-Tecnológica (PCT) nacional, destacando-se que o tema Infraestrutura surgiu dos problemas da comunidade dos educandos e necessita de conhecimentos científicos e tecnológicos para sua compreensão, possibilitando, com isso, que os alunos participem das tomadas de decisão sobre uma PCT nacional, dado que a participação nestas decisões exige que os sujeitos compreendam os problemas locais existentes. Como exemplo desse processo tem-se a produção de documentos elaborados

8 Este movimento conhecido como o Placts, que se caracterizou como sendo uma das naturezas do tema Infraestrutura, surgiu da insatisfação por parte da comunidade acadêmica da América Latina, mais especificamente de professores universitários argentinos das áreas das Ciências Naturais e Exatas, com a concepção tradicional da ciência e da tecnologia. Com isso, estes professores mobilizaram-se em prol do que denominaram de um "projeto nacional" que contivesse um importante desafio relativo à ciência e tecnologia. O Placts fornece elementos para a elaboração de parâmetros para definição de uma PCT que abarque a necessidade de fortalecer a estrutura de pesquisa e desenvolvimento de Ciência e Tecnologia (CT) que atenda interesses de demanda locais (ROSO, 2014; AULER, 2011; DAGNINO, 2013). 
pelos educandos durante a instituição do tema, sendo elaboradas cartas em que os educandos mostravam suas insatisfações com os problemas por eles vivenciados e também apresentando possíveis soluções para tais problemas. Os documentos estavam direcionados aos órgãos e pessoas, que, no entender dos estudantes, eram responsáveis pelos problemas apresentados. Com isso, o tema Infraestrutura caracteriza-se também como um tema de natureza Freire $\mathrm{x}$ Placts (ARAÚJO; MUENCHEN, 2014).

Após este processo de ER no qual emergiu o tema Infraestrutura, os docentes passaram ao segundo e terceiro Momento Pedagógico, ou seja, a Organização do Conhecimento e a Aplicação do Conhecimento (ARAÚJO, 2015). Mesmo não sendo foco do presente trabalho, que procurou explorar a dinâmica dos 3MP para chegar ao tema gerador Infraestrutura, convém destacar alguns conceitos científicos trabalhados para a compreensão do tema. São eles: vasos comunicantes, unidades de medidas e de volumes, vazão e equação de Bernoulli, pressão do fluido e fluxo, densidade, massa específica, ângulos, porcentagem e tensão superficial.

\section{Considerações Finais}

Constata-se que, com o desenvolvimento do Estudo da Realidade, foi possível visualizar, vivenciar e investigar os problemas vividos pela comunidade, contribuindo assim, com a formação crítica da cidadania dos educandos da escola em que o projeto foi desenvolvido a partir do tema gerador Infraestrutura.

Ressalta-se que a realização deste trabalhou não foi trivial, exigindo de todos os envolvidos neste processo comprometimento, empenho, dedicação e determinação para que fosse possível vencer entraves como a falta de tempo e as condições de trabalho, além de que este processo exigiu muitos encontros que não constavam no cronograma do curso de formação, sendo destinados a realização de visitas nas casas, comércios e posto de saúde. A falta de tempo tornou-se uma limitação para a participação de outros docentes no projeto, impossibilitando com isso que o envolvimento de outras áreas se fizesse presente. Mesmo, porém, com alguns impasses enfrentados, destaca-se que com o desen- 
volvimento do ER as docentes além de se sentirem investigadoras da realidade dos educandos - possibilitando com isso uma aproximação com os alunos -, este momento proporcionou-lhes uma reflexão acerca de seus reais papéis como docentes, incluindo a participação na estruturação curricular da escola.

Mesmo não sendo objeto de análise do presente artigo, destaca-se que ocorreram atividades nas aulas desenvolvidas para que fosse possível um novo olhar dos educandos sobre a comunidade investigada. Estas atividades remetem a trabalhos como: elaboração de maquetes sobre a rede de esgoto e a produção de um documento 9 a ser enviado às autoridades responsáveis pelos problemas detectados na comunidade e que foram discutidos em aula - as autoridades ${ }^{10}$ responsáveis pelos problemas discutidos foram indicadas pelos educandos a partir das discussões realizadas em sala de aula - sendo estas atividades construídas na busca por uma transformação da realidade dos alunos.

É importante destacar que a dinâmica dos 3MP como estruturadora de currículos, vinculada à AT, apresenta subsídios para que educador e educandos construam o conhecimento a partir de problemas próximos à vida dos alunos, permitindo, com isso, que eles se sintam sujeitos ativos no processo de elaboração de seus conhecimentos. Outro aspecto importante de se ressaltar é que o processo de ER, primeira fase do desenvolvimento curricular, não é uma etapa que se encontra pronta para ser executada, esta deve ser construída a partir da realidade que se deseja investigar. Os materiais que farão parte do dossiê devem ser elaborados pelos sujeitos envolvidos no processo, assim como ocorreu no presente trabalho.

9 Ressalta-se, aqui, que os documentos produzidos pelos estudantes não foram entregues aos responsáveis. Assim, como sinalização para continuação deste trabalho, pretende-se que os educandos, juntamente com a pesquisadora e as docentes que desenvolveram as atividades, entreguem estes documentos aos responsáveis.

${ }^{10}$ As autoridades responsáveis pelos problemas escolhidas pelos educandos foram o prefeito da cidade de Santa Maria e o secretário de Obras e Planejamento. 
Por fim, ao adotar referenciais como os mencionados neste artigo, torna-se possível aproximar-se de uma educação pautada no diálogo e na problematização de questões próximas à vida dos educandos, potencializando uma relação mais próxima entre o "mundo da escola" e o "mundo da vida".

\section{Referências}

ANGOTTI, J. A. Solução alternativa para a formação de professores de ciências: um projeto educacional desenvolvido na Guiné-Bissau. Dissertação de mestrado. São Paulo: IFUSP/FEUSP, 1982.

ARAÚJO, L. B. Os três momentos pedagógicos como estruturantes de currículo. 2015. Dissertação (Mestrado em Educação em Ciências: Química da Vida e Saúde) - Santa Maria: PPGECQV/CCNE/UFSM, 2015.

ARAÚJO, L. B.; MUENCHEN, C. O tema gerador "infraestrutura" e sua relação com o Pensamento Latino-Americano em Ciência, Tecnologia e Sociedade (Placts). In: SEMINÁRIO INTERNACIONAL DE EDUCAÇÃO EM CIÊNCIAS, 3, 2014. Rio Grande. Anais eletrônicos... Rio Grande, RS: Furg, 2014. Disponível em: <http://www.casaleiria. com.br/sintec3/sintec3.htm>.

. Um olhar sobre o Movimento de Reorientação Curricular: a posição dos docentes em relação ao projeto. In: SEMINÁRIO DIÁLOGOS COM PAULO FREIRE, 7., 2013, Rio Grande. Anais... Rio Grande, RS, 2013.

AULER, D. Novos caminhos para a educação CTS: ampliando a participação. In: AULER, D.; SANTOS, W. L. P. (Org.). CTS e educação científica: desafios, tendências e resultados de pesquisa. Brasília: UnB, 2011. p. 73-97.

. Articulação entre pressupostos do educador Paulo Freire e do Movimento CTS: novos caminhos para a educação em ciências. Contexto e Educação, Ijuí, RS: Ed. Unijuí, v. 1, n. 1 , p. $167-188,2007$ a.

. Enfoque Ciência-Tecnologia-Sociedade: pressupostos para o contexto brasileiro. Ciência \& Ensino, v. 1, número especial, nov. 2007b.

DAGNINO, R. O que é Placts (Pensamento Latino-Americano em Ciência, Tecnologia e Sociedade)? In: NEDER, R. T. (Org.). CTS - ciência, tecnologia, sociedade e a produção de conhecimento na universidade. Brasília: UnB, 2013. p. 35-52.

DELIZOICOV, D. Conhecimento, tensões e transições. 1991. Tese (Doutorado) - Feusp, São Paulo, 1991. 
DELIZOICOV, D. Concepção problematizadora do ensino de ciências na educação formal. 1982. Dissertação (Mestrado) - Ifusp/Feusp. São Paulo, 1982.

. Uma experiência em ensino de ciência na Guiné-Bissau Depoimento. Revista de Ensino de Física, v. 2, n. 4, dez. 1980.

DELIZOICOV, D.; ANGOTTI, J. A.; PERNAMBUCO, M. M. Ensino de ciências: fundamentos e métodos. 4. ed. São Paulo: Cortez, 2011.

FREIRE, P. Pedagogia do oprimido. 50. ed. Rio de Janeiro: Paz e Terra, 2011.

. Pedagogia da esperança: um reencontro com a pedagogia do oprimido. 16. ed. Rio de Janeiro: Paz e Terra, 1992.

FREIRE, P.; SHOR, I. Medo e ousadia: o cotidiano do professor. 13. ed. Rio de Janeiro: Paz e Terra, 2011.

GIACOMINI, A. Intervenções curriculares na perspectiva da Abordagem Temática: avanços alcançados por professores de uma escola pública estadual do RS. 2014. Dissertação (Mestrado em Educação em Ciências: Química da Vida e Saúde) - PPGECQV/ CCNE/UFSM, Santa Maria, 2014.

GIL, A. C. Como elaborar projeto de pesquisa. 4. ed. São Paulo: Editora Atlas, 2002.

HALMENSCHLAGER, K. Abordagem de temas em Ciências da Natureza no Ensino Médio: implicações na prática e na formação docente. 2014. Tese (Doutorado) - Programa de Pós-Graduação em Educação Científica e Tecnológica, UFSC/PPGECT, Florianópolis, 2014.

MUENCHEN, C. A disseminação dos Três Momentos Pedagógicos: um estudo sobre práticas docentes na região de Santa Maria/RS. 2010. Tese (Doutorado) - Programa de Pós-Graduação em Educação Científica e Tecnológica, UFSC/PPGECT, Florianópolis, 2010.

. Configurações curriculares mediante o enfoque CTS: desafios a serem enfrentados na EJA.2006. Dissertação (Mestrado em Educação) - PPGE/CE/UFSM, Santa Maria, 2006.

MUENCHEN, C.; AULER, D. Abordagem temática: desafios na educação de jovens e adultos. Revista Brasileira de Pesquisa em Educação em Ciências, vol. 7, n. 3, p. 1-17, 2007.

MUENCHEN, C.; DELIZOICOV, D. A construção de um processo didático-pedagógico dialógico: aspectos epistemológicos. Ensaio: Pesquisa em Educação em Ciências (on-line), Belo Horizonte, MG, v. 14, n. 3, p. 199-215, set./dez. 2012.

PERNAMBUCO, M. M. Educação e escola como movimento: do ensino de ciências à transformação da escola pública. 1994. Tese (Doutorado) - Feusp, São Paulo, 1994. 
RIO GRANDE DO SUL. Instituto Estadual Luiz Guilherme do Prado Veppo. Projeto Político Pedagógico. Santa Maria: 2011.

ROSO, C. A participação na construção do currículo: práticas educativas vinculadas ao movimento CTS. 2014. Dissertação (Mestrado em Educação) - PPGE/CE/UFSM, Santa Maria, 2014.

SÃO PAULO. Cadernos de Formação 01, 02 e 03. Série Ação Pedagógica na escola pela via da interdisciplinaridade. Secretaria Municipal de Educação. São Paulo: DOT/ SME-SP, 1990.

TORRES, C. A.; O'CADIZ, M. P.; WONG. P. L. Educação e democracia: a práxis de Paulo Freire em São Paulo. São Paulo: Cortez; Instituto Paulo Freire, 2002.

Recebido em: $1 \% / 8 / 2016$

Aceito em: 26/1/2017 


\section{Anexo 1 - Entrevistas que compõem o dossiê do Estudo da Realidade}

\section{Questionário Comunidade}

1) Existe rede de esgoto em seu bairro? De onde vem a água que você consome?

2) Há coleta de lixo? Como isso ocorre?

3) Quantas pessoas residem aqui? Quantos contribuem para o sustento da família? Qual sua fonte de renda?

4) Como vem sendo o atendimento da saúde em seu bairro? Existem visitas domiciliares de agentes de saúde? Como ela é feita?

5) Você se sente seguro no bairro em que reside? Por quê?

6) Qual sua opinião em relação à utilização do transporte coletivo? São necessárias mudanças? Quais?

7) O que você costuma fazer em suas horas de lazer? O bairro dispõe de espaço público para lazer?

8) Qual sua relação com a escola? Você costuma frequentá-la? Em que momentos? Como você vê a relação entre comunidade x escola?

9) Na sua opinião, qual o principal problema enfrentado pela comunidade? Qual seria a solução para este problema?

10) Por que você escolheu morar aqui? Você gosta de morar neste bairro? O que você gostaria que fosse diferente?

Questionário Posto de Saúde

1) Qual o horário de atendimento?

2) Como ocorre esse atendimento: por horário ou por quantidade de pacientes?

3) Quantos médicos o posto possui? Quais as especialidades?

4) Há uma estrutura adequada para a espera dos pacientes?

5) Qual a estrutura física do posto? 
6) Como se dá o encaminhamento para aqueles pacientes que o posto não dispõe de subsídios para atendê-los?

7) Quais os principais fatores que levam a comunidade a procurar o posto de saúde?

8) Como ocorre a relação entre comunidade/posto de saúde?

9) Qual a demanda por métodos contraceptivos?

10) Quais as dificuldades enfrentadas pelo posto para melhor atender à comunidade?

11) Quais os maiores problemas que você apontaria dessa comunidade? O que poderia ser feito para resolvê-los?

\section{Questionário Equipe Diretiva}

1) Quais são os objetivos da escola? Qual a formação que a escola deseja para seus alunos? Esta formação vem sendo buscada? Como isso está acontecendo?

2) O trabalho da escola vem ocorrendo a partir da interdisciplinaridade? Comente.

3) São dados subsídios para que este trabalho interdisciplinar ocorra de forma adequada?

4) De que forma a escola interage com a comunidade? Quais são as ações da escola para se aproximar da comunidade?

5) Como se dá a relação entre a equipe diretiva e os alunos? E com os professores e funcionários?

6) Quais os principais problemas enfrentados pela escola? Como esta vem trabalhando para superar tais dificuldades?

7) Um bom trabalho pode ficar comprometido pela falta de estrutura física da escola?

8) A escola dispõe de associações estudantis? Quais?

9) Qual o maior problema enfrentado no bairro em que a escola está inserida? 


\section{Questionário Professores}

1) Qual disciplina você leciona?

2) Qual a proposta desta escola?

3) O que você entende por interdisciplinaridade?

4) Como ocorre sua relação com a equipe diretiva, funcionários e com os alunos?

5) Você conhece a realidade de seus alunos? De que forma? E da comunidade na qual a escola está inserida?

6) Para você, quais os maiores problemas enfrentados na escola? Por quê?

7) Qual sua contribuição para a aproximação da escola com a comunidade?

8) Há segurança na escola?

9) O que você mudaria na escola?

10) Qual o maior problema enfrentado no bairro em que a escola está inserida?

\section{Questionário Funcionários}

1) Há segurança na escola?

2) Como ocorre sua relação com a equipe diretiva, professores e alunos?

3) Como você participa das tomadas de decisão da escola?

4) Você dispõe de uma estrutura adequada para realização de suas atividades? Por quê?

5) O que você mudaria na escola?

6) Qual o maior problema enfrentado no bairro em que a escola está inserida?

Questionário Estudantes

1) Qual sua idade? Que série você frequenta?

2) Quais seus objetivos de vida?

3) Por que você frequenta a escola? 
4) O que você busca na escola? Qual a relação entre o que você busca com aquilo que a escola the oferece?

5) Como é sua relação com os professores, funcionários e equipe diretiva?

6) Você tem oportunidades de se manifestar na escola? Em que momentos?

7) O que você costuma fazer em suas horas de lazer? O bairro dispõe de espaço público para lazer?

8) Na sua opinião, qual o principal problema enfrentado pela comunidade? Qual seria a solução para este problema?

9) Você se sente seguro no bairro em que reside? Por quê?

10) Existem conflitos na escola? Qual sua atitude em relação a essa situação?

11) Como vem sendo o atendimento da saúde em seu bairro?

12) Você recebe orientações para prevenção de DSTs, gravidez? De que forma e onde?

13) O que você mudaria em seu bairro?

14) Qual sua opinião em relação à utilização do transporte coletivo? São necessárias mudanças? Quais?

15) O que você mudaria na escola? 